\title{
Management of dyslipidemia and hyperglycemia with a fixed-dose combination of sitagliptin and simvastatin
}

This article was published in the following Dove Press journal:

Vascular Health and Risk Management

28 May 2013

Number of times this article has been viewed

\section{Helmut Steinberg \\ Matt S Anderson \\ Thomas Musliner \\ Mary E Hanson \\ Samuel S Engel}

Merck Sharp \& Dohme Corp.,

Whitehouse Station, NJ, USA
Correspondence: Samuel Engel Merck Sharp \& Dohme Corp.

I26 E Lincoln Avenue, PO Box 2000, RY34-A232, Rahway, NJ 07065, USA

$\mathrm{Tel}+\mathrm{I} 732594098$ I

Fax +l 7325943560

Email samuel.engel@merck.com
Abstract: The risk of death due to heart disease and stroke is up to four times higher in individuals with diabetes compared to individuals without diabetes. Most guidelines that address treatment of dyslipidemia in patients with diabetes consider diabetes a cardiovascular disease (CVD) "risk equivalent" and recommend intensive treatment of dyslipidemia for the purpose of CVD prevention. Statins (3-hydroxy 3-methylglutaryl coenzyme A reductase [HMG-CoA reductase] inhibitors) are first-line agents in achieving lipid goals as an adjunct to diet and exercise and should be used in most patients. In addition to lipid management and blood pressure control, glycemic control is a basic component in the management of diabetes. Glycemic control is achieved by combining diabetes self-management education, diet and exercise, and, where required, antihyperglycemic agents (OHAs). Persistence and adherence to therapy are critical in achieving recommended treatment goals. However, overall compliance with concomitantly prescribed OHAs and statins is low in patients with type 2 diabetes. Fixed-dose combination (FDC) therapies have been shown to improve adherence by reducing pill burden, the complexity of treatment regimen, and, potentially, cost. Based on the available evidence regarding the pharmacokinetics and the efficacy and safety profiles of each component drug, the sitagliptin/ simvastatin FDC may provide a rational and well-tolerated approach to achieving better adherence to multiple-drug therapy and improved lipid lowering and glycemic control, with consequent reduction in cardiovascular risk, diabetic microvascular disease, and mortality in diabetic patients for whom treatment with both compounds is appropriate.

Keywords: statin, oral antihyperglycemic agent, diabetes, adherence, cardiovascular disease, microvascular disease

\section{Introduction}

The International Diabetes Federation estimates that there are approximately 371 million people in the world living with diabetes, of whom half are undiagnosed. ${ }^{1}$ In the United States and Europe, the prevalence of this disease is $10.5 \%$ and $6.7 \%$ of the population, respectively. ${ }^{1}$ The risk of death due to heart disease and stroke is up to four times higher in individuals with diabetes compared to individuals without diabetes. ${ }^{2}$ Additional serious long-term consequences associated with diabetes include renal failure, retinopathy, and neuropathy.

Dyslipidemia is a major predisposing factor for atherosclerotic cardiovascular disease (CVD) in the general population as well as in diabetic patients. Elevations in low-density lipoprotein cholesterol (LDL-C) have received the greatest attention from the scientific and clinical community, and it is clear that LDL-C level is at least as strong a predictor of coronary heart disease risk in diabetic patients as it is 
in the general population. ${ }^{3}$ In the UK Prospective Diabetes Study, a 57\% increased risk of coronary heart disease was reported for every $1 \mathrm{mmol} / \mathrm{L}$ increment in LDL-C. ${ }^{4,5}$ While LDL-C is not often greatly increased in diabetic individuals, the presence of diabetes and/or insulin resistance is associated with profound changes in lipid and lipoprotein metabolism, with resultant alterations in particle distribution within lipoprotein classes. This includes increased numbers of small dense LDL particles, ${ }^{6}$ which are believed to be particularly atherogenic due to their increased endothelial permeability, susceptibility to oxidation and glycation, and ability to bind to proteoglycans in the vessel wall. ${ }^{7-9}$ Many diabetic patients also have increased levels of larger apolipoprotein B-containing lipoproteins, including very low-density lipoprotein remnants of intermediate density, as well as reduced levels of high-density lipoprotein cholesterol (HDL-C), both of which are associated with increased CVD risk. $^{6,10}$

Because of this increased CVD risk, most guidelines that address treatment of dyslipidemia in patients with diabetes (including those from the American Diabetes Association and American College of Cardiology Foundation guidelines, the Task Force on Diabetes and Cardiovascular Diseases of the European Society of Cardiology, and the European Association for the Study of Diabetes) consider diabetes as a CVD "risk equivalent" and recommend intensive treatment of dyslipidemia for the purpose of CVD prevention. ${ }^{6,11-13}$ These treatment guidelines provide goals for lipids and glucose levels. LDL-C has been identified as the primary therapeutic target for patients with hypercholesterolemia, existing CVD, or other CVD risk factors. ${ }^{12,14,15}$ The Canadian Cardiovascular Society guidelines recommend an LDL-C target of $\leq 77 \mathrm{mg} / \mathrm{dL}(2.0 \mathrm{mmol} / \mathrm{L})$ or $\geq 50 \%$ decrease in LDL-C in all risk categories when pharmacologic intervention is warranted. ${ }^{14}$ However, the US and European guidelines have designated different LDL-C target levels based on CVD risk. ${ }^{12,15}$ Specifically, attaining LDL-C $\leq$ $100 \mathrm{mg} / \mathrm{dL}(\leq 2.6 \mathrm{mmol} / \mathrm{dL})$ is recommended for those at high or moderate CVD risk, and the more aggressive target of $\leq 70 \mathrm{mg} / \mathrm{dL}$ ( $\leq 1.8 \mathrm{mmol} / \mathrm{dL})$ is recommended for patients at very high risk for CVD, including those with diabetes and overt CVD. ${ }^{12,15,16}$

Statins (3-hydroxy 3-methylglutaryl coenzyme A reductase [HMG-CoA reductase] inhibitors) are first-line agents in achieving lipid goals if diet and exercise are not sufficient, since they are generally well tolerated, highly effective for lowering LDL-C, and have been shown to be capable of substantially decreasing cardiovascular mortality and morbidity. ${ }^{17-19}$ A meta-analysis of 14 randomized trials, which included $\sim 90,000$ subjects, demonstrated that for every $1.0 \mathrm{mmol} / \mathrm{L}$ reduction in LDL-C achieved, there was an approximate $20 \%$ reduction in coronary heart disease mortality and a $22 \%$ reduction in major CVD events. ${ }^{20}$ These results were consistent across baseline LDL-C levels and similar in subjects with and without diabetes. ${ }^{20,21}$

In addition to lipid management and blood pressure control, glycemic control is a basic component in the management of diabetes and is achieved, in part, via diabetes self-management education, exercise, and improved diet, the latter elements being the cornerstones of treatment for diabetes and high lipid levels. Guidelines for the treatment of diabetes stress the importance of lowering $\mathrm{HbA}_{1 \mathrm{C}}$ to a level below $7 \%$ in non-pregnant adults in order to reduce the risk of microvascular (retinopathy and nephropathy) and neuropathic complications. ${ }^{16,22}$ Analyses have suggested that lowering $\mathrm{HbA}_{1 \mathrm{C}}$ to $6 \%$ is associated with further reductions in the risk of microvascular complications, albeit with substantially increased risk of hypoglycemia. ${ }^{23,24}$ According to these guidelines, intensive $\mathrm{HbA}_{1 \mathrm{C}}$ lowering beyond $7 \%$ may be warranted in selected individuals. In patients with little comorbidity and with long life expectancy, the patient and physician may opt for glycemic targets as close to normal as possible as long as hypoglycemia does not pose a significant problem. ${ }^{16}$

Even if patients are treated according to the guidelines with proven treatments, the treatments can only be maximally effective if patients are adherent to the treatment regimen. Persistence and adherence to therapy are critical in achieving recommended treatment goals and improving patient outcomes in chronic conditions such as type 2 diabetes mellitus. ${ }^{6,11}$ It has been shown that nonadherence to medication is associated with significantly $(P<0.001)$ higher all-cause hospitalization and mortality in diabetic patients, ${ }^{25}$ and overall compliance with oral antihyperglycemic agents (OHAs) is low in patients with type 2 diabetes. ${ }^{26}$ Several cross-sectional retrospective analyses estimated that adherence to statins tends to be even lower compared with adherence to OHAs in patients who receive them as concomitant therapy (with adherence rates estimated around $52 \%$ for statins to $72 \%$ for OHAs). ${ }^{27-30}$

The reasons for differences in adherence between OHAs and statins are complex and not well understood, and several variables play a role in a patient's compliance with a prescribed treatment plan. ${ }^{31}$ One potential reason for greater adherence to OHAs versus statins may be the difference in associated symptoms. Dyslipidemia is generally 
asymptomatic and less likely to be discussed between a patient and health care provider, whereas glycemic abnormalities often have associated symptoms that may cause apprehension. ${ }^{11,32,33}$ Moreover, there may be a perception on the part of the patient that the purpose of statins is to lower cholesterol rather than to reduce cardiovascular risk; since LDL-C and total cholesterol are generally similar in patients with and without type 2 diabetes ${ }^{34}$ lipid control may not raise the same level of concern as glucose control. Finally, there may be a perceived lack of benefit from statins on the part of the patient, ${ }^{35,36}$ whereas the benefit from OHAs in relation to glucose control may be easily seen by patients as they self-monitor blood glucose.

Fixed-dose combination (FDC) therapies have been shown to improve adherence by reducing costs, pill burden, and the complexity of treatment regimen. ${ }^{37-39} \mathrm{~A}$ treatment approach with a FDC that includes a statin and an OHA could be used to improve statin compliance in patients with type 2 diabetes. Sitagliptin (Januvia [Merck, Whitehouse Station, NJ, USA]) is a highly selective dipeptidyl peptidase-4 (DPP4) inhibitor available for the treatment of hyperglycemia in patients with type 2 diabetes, ${ }^{40,41}$ and simvastatin (Zocor ${ }^{\mathrm{TM}}$ [Merck]) is an HMG-CoA reductase inhibitor available as an adjunctive treatment to diet for reducing elevated LDL-C and other lipids in patient with primary hypercholesterolemia and is indicated for reducing the risk of cardiovascular mortality. ${ }^{42}$ An FDC tablet of sitagliptin and simvastatin (Juvisync ${ }^{\mathrm{TM}}$ [Merck]) has been approved and provides an option for use in patients for whom treatment with both sitagliptin and simvastatin is appropriate.

\section{Pharmacological profile of Juvisync ${ }^{\mathrm{TM}}$}

The separate pharmacokinetic profiles of sitagliptin and simvastatin have been extensively characterized in healthy subjects, and previously reviewed; ${ }^{43,44}$ however, there is no published literature discussing the pharmacokinetic profile of the FDC tablet of sitagliptin/ simvastatin, which is formed by compressing a common sitagliptin blend with a common simvastatin granule to form a bilayer tablet. The FDC tablet is available in doses of (sitagliptin/simvastatin) $100 \mathrm{mg} / 10 \mathrm{mg}$, $100 \mathrm{mg} / 20 \mathrm{mg}$, and $100 \mathrm{mg} / 40 \mathrm{mg}$, as well as dosages for patients with moderate renal insufficiency $(50 \mathrm{mg} / 10 \mathrm{mg}$, $50 \mathrm{mg} / 20 \mathrm{mg}$, and $50 \mathrm{mg} / 40 \mathrm{mg}$ ).

The potential for simvastatin to alter sitagliptin pharmacokinetics was explored in an open-label randomized two-period crossover study in ten healthy men and women, wherein the pharmacokinetics of sitagliptin were compared after administration of a single dose of sitagliptin $100 \mathrm{mg}$ alone or in the presence of steady state simvastatin (on day 5 of a 7-day course of simvastatin $80 \mathrm{mg}$ once daily). ${ }^{45}$ Simvastatin had no clinically relevant effect on sitagliptin: the geometric mean ratio of (sitagliptin + simvastatin)/sitagliptin ( $90 \%$ confidence interval $[\mathrm{CI}])$ of $\mathrm{AUC}_{0-\infty}=1.01(0.97,1.05)$ and $\mathrm{C}_{\max }=1.12(90 \% \mathrm{CI} 1.00,1.26)$. Conversely, the potential for sitagliptin to alter simvastatin pharmacokinetics was explored in an open-label randomized two-period crossover study in 12 healthy men and women, wherein the pharmacokinetics of simvastatin were compared after administration of a single dose of simvastatin $20 \mathrm{mg}$ alone or in the presence of steady state sitagliptin (on day 5 of a 5-day course of sitagliptin $200 \mathrm{mg}$ once daily). ${ }^{46}$ Sitagliptin had no clinically meaningful effect on simvastatin: the geometric mean ratio of (simvastatin lactone + sitagliptin)/simvastatin lactone $(90 \%$ CI) of $\mathrm{AUC}_{0 \text {-last }}=0.85(0.60,1.22), \mathrm{C}_{\max }=0.80(0.51,1.26)$, and, for simvastatin acid $\mathrm{AUC}_{0 \text {-last }}=1.12(0.93,1.35)$ and $\mathrm{C}_{\max }=1.06(0.86,1.32) .{ }^{46}$ Consequently, no dose adjustments are recommended for these drugs when coadministered. ${ }^{46}$

A demonstration of definitive bioequivalence between the FDC tablet of sitagliptin/simvastatin at two tablet strengths $(100 \mathrm{mg} / 10 \mathrm{mg}$ and $100 \mathrm{mg} / 80 \mathrm{mg}$ ) as compared to coadministration of the corresponding doses of sitagliptin and simvastatin as individual tablets was conducted in two separate open-label randomized two-period single-dose definitive bioequivalence studies presented in this review. Primary endpoints were to compare the pharmacokinetics of sitagliptin (using $\mathrm{AUC}_{0-\infty}$ and $\mathrm{C}_{\max }$ ), simvastatin lactone (using $\mathrm{AUC}_{0 \text {-last }}$ and $\mathrm{C}_{\max }$ ), and simvastatin acid (using $\mathrm{AUC}_{0-\text { last }}$ and $\left.\mathrm{C}_{\max }\right)$, using $[0.80,1.25]$ as allowable bounds of variation for each analyte. Both studies enrolled 100 healthy subjects ranging in age from 18 to 55 years (Table 1). The $90 \%$ CIs of the observed geometric mean ratios (GMR) (Juvisync $^{\mathrm{TM}} /[$ sitagliptin + simvastatin $]$ ) for the $\mathrm{AUC}_{0-\infty}$ and $\mathrm{C}_{\max }$ of sitagliptin and the $\mathrm{AUC}_{0 \text {-last }}$ and $\mathrm{C}_{\max }$ of simvastatin lactone and simvastatin acid were all within the prespecified bounds in both studies, demonstrating bioequivalence of the FDC tablet and the individual tablets across the assessed dose range (Table 2). Demonstration of bioequivalence for all other manufactured tablet strength combinations, as compared to their separately administered components, was supported through in vitro dissolution data and formulationproportionality arguments.

The potential for pharmacokinetic interactions between the FDC tablet and digoxin were also investigated as previously conducted pharmacokinetic-interaction studies of single-dose digoxin, administered with and without mul- 
Table I Subject disposition in bioequivalence studies

\begin{tabular}{|c|c|c|}
\hline Patient characteristics & $\begin{array}{l}100 \mathrm{mg} \text { sitagliptin/ } \\
\text { I } 0 \mathrm{mg} \text { simvastatin }\end{array}$ & $\begin{array}{l}100 \mathrm{mg} \\
\text { sitagliptin/ } \\
80 \mathrm{mg} \\
\text { simvastatin }\end{array}$ \\
\hline Total patients randomized (n) & 100 & 100 \\
\hline Male age (range) in years & $41(19-54)$ & $61(20-55)$ \\
\hline Female age (range) in years & $59(18-53)$ & $39(20-55)$ \\
\hline Completed (n) & 93 & 98 \\
\hline Discontinued (n) & 7 & 2 \\
\hline Clinical AEs (n) & 0 & 0 \\
\hline Laboratory AEs (n) & 0 & 0 \\
\hline Withdrew consent (n) & 6 & 0 \\
\hline Protocol violation (n) & $\mathrm{I}$ & 2 \\
\hline
\end{tabular}

Abbreviation: AEs, adverse events.

tiple doses of sitagliptin or of simvastatin, showed that each medication slightly increased the plasma pharmacokinetics of digoxin relative to digoxin administered alone. Consistent with these earlier investigations, concomitant administration of multiple doses of sitagliptin $100 \mathrm{mg}$ and simvastatin $80 \mathrm{mg}$ with a single $0.5 \mathrm{mg}$ dose of digoxin moderately increased the plasma $\mathrm{AUC}_{0 \text {-last }}$ of digoxin (Table 3), demonstrating that multiple-dose coadministration of sitagliptin/simvastatin $100 \mathrm{mg} / 80 \mathrm{mg}$ had a roughly additive pharmacokinetic effect

Table 2 Statistical comparisons for the plasma PK parameters of sitagliptin, simvastatin, and simvastatin acid after a single-dose administration of FDC sitagliptin/simvastatin $100 \mathrm{mg} / 10 \mathrm{mg}$ or $100 \mathrm{mg} / 80 \mathrm{mg}$ tablet, or coadministration of corresponding doses of sitagliptin and simvastatin and individual tablets

\begin{tabular}{|c|c|c|c|c|}
\hline \multirow[t]{2}{*}{ PK parameter } & \multicolumn{2}{|c|}{$\begin{array}{l}100 \mathrm{mg} / 10 \mathrm{mg} \\
\mathrm{FDC} / 100 \mathrm{mg}+ \\
10 \mathrm{mg}\end{array}$} & \multicolumn{2}{|c|}{$\begin{array}{l}100 \mathrm{mg} / 80 \mathrm{mg} \\
\mathrm{FDC} / 100 \mathrm{mg}+ \\
80 \mathrm{mg}\end{array}$} \\
\hline & GMR & $90 \% \mathrm{Cl}$ & GMR & $90 \% \mathrm{Cl}$ \\
\hline \multicolumn{5}{|l|}{ Sitagliptin } \\
\hline $\mathrm{AUC}_{0-\infty}\left(\mathrm{nM} \mathrm{M}^{*} \mathrm{hr}\right)$ & 1.01 & $(0.99,1.02)$ & 0.99 & $(0.98,1.00)$ \\
\hline $\mathrm{AUC}_{0 \text {-last }}(\mathrm{nM} * \mathrm{hr})$ & 1.01 & $(1.00,1.03)$ & 0.99 & $(0.98,1.00)$ \\
\hline$C_{\max }(n M)$ & 1.03 & $(0.98,1.07)$ & 0.98 & $(0.94,1.02)$ \\
\hline \multicolumn{5}{|l|}{ Simvastatin } \\
\hline $\mathrm{AUC}_{0 \text {-last }}(\mathrm{nM} * \mathrm{hr})$ & 1.07 & $(0.99,1.16)$ & 0.99 & $(0.93,1.05)$ \\
\hline$C_{\max }(n M)$ & 1.13 & $(1.05,1.21)$ & 0.98 & $(0.92,1.06)$ \\
\hline \multicolumn{5}{|l|}{ Simvastatin acid } \\
\hline $\mathrm{AUC}_{0 \text {-last }}\left(\mathrm{nM} \mathrm{M}^{*} \mathrm{hr}\right)$ & 1.03 & $(0.96,1.11)$ & 0.93 & $(0.87,0.98)$ \\
\hline$C_{\text {max }}(n M)$ & 1.04 & $(0.97,1.12)$ & 0.95 & $(0.88,1.02)$ \\
\hline
\end{tabular}

Notes: The PK parameter values following a single-dose administration of study drug were compared using separate linear mixed-effect models appropriate for a two-period crossover design. The linear mixed-effect model contained factors for sequence, period, and treatment as fixed effects, and subject-within-sequence as a random effect. A log transformation was applied to the AUC and $C_{\max }$ data. Back-transformed summary statistics and inferential results were reported for PK parameter values. The $90 \% \mathrm{Cls}$ were compared to the prespecified bounds of $[0.80$, I.25]. *represents multiplication.

Abbreviations: $\mathrm{AUC}$, area under the curve; $\mathrm{C}$, concentration; $\mathrm{Cl}$, confidence interval; FDC, fixed-dose combination; GMR, geometric mean ratio; PK, pharmacokinetic.
Table 3 Statistical comparisons for the plasma PK parameters after administration of a single dose of digoxin $0.5 \mathrm{mg}$ alone or sitagliptin $100 \mathrm{mg}$ once daily and simvastatin $80 \mathrm{mg}$ once daily for 9 days and a single dose of digoxin $0.5 \mathrm{mg}$ on day 5 in healthy male and female subjects

\begin{tabular}{lll}
\hline PK parameter & \multicolumn{2}{l}{$\begin{array}{l}\text { (Digoxin + sitagliptin + } \\
\text { simvastatin)/digoxin }\end{array}$} \\
\cline { 2 - 3 } & GMR & $\mathbf{9 0 \% ~ C l}$ \\
\hline $\mathrm{AUC}_{0 \text {-lass }}\left(\mathrm{nM} \mathrm{n}^{*} \mathrm{hr}\right)$ & 1.26 & $(\mathrm{I} .13,1.4 \mathrm{I})$ \\
$\mathrm{C}_{\max }(\mathrm{nM})$ & $1.4 \mathrm{I}$ & $(1.20,1.66)$ \\
\hline
\end{tabular}

Notes: Back-transformed least-squares mean and $\mathrm{Cl}$ from linear mixed-effects model performed on natural log-transformed values. The effects and variability due to subjects within sequence (a random effect) and sequence, period, and treatment (fixed effects), as well as the within-subject variability of the PK parameters were estimated using a mixed-effect analysis model appropriate for the two-period study design. A log transformation was applied to the digoxin $A \cup C_{0 \text {-last }}$ and $C_{\max }$ data. $\mathrm{A} 90 \% \mathrm{Cl}$ was constructed for the difference in least-squares means on the log scale. Exponentiation of the log scale $90 \% \mathrm{Cl}$ provided a $90 \% \mathrm{Cl}$ for the GMR ([digoxin + sitagliptin + simvastatin]/digoxin alone). The $90 \% \mathrm{Cls}$ were compared to the prespecified bounds of $[0.80,1.25]$. Summary statistics and comparisons were provided for $\mathrm{C}_{\max }$ of digoxin.

Abbreviations: AUC, area under the curve; $\mathrm{C}$, concentration; $\mathrm{Cl}$, confidence interval; GMR; geometric least-squares mean ratio ([digoxin + simvastatin + sitagliptin]/digoxin); PK, pharmacokinetic.

on the single-dose pharmacokinetics of digoxin relative to digoxin administration with either sitagliptin or simvastatin alone. However, these effects are not considered clinically important in the context of appropriate monitoring as already recommended in clinical practice with digoxin. Accordingly, patients receiving digoxin concomitantly with Juvisync ${ }^{\mathrm{TM}}$ should be monitored appropriately by their physician as if they were receiving digoxin alone or in combination with either simvastatin or sitagliptin alone.

\section{Efficacy}

The rationale for using OHAs such as sitagliptin is to improve glucose control, thereby reducing the risk of microvascular disease without inducing hypoglycemia or weight gain in patients with type 2 diabetes. The rationale for using a statin (such as simvastatin) is to improve lipid and lipoprotein levels to within individual therapeutic targets, thereby reducing $\mathrm{CV}$ morbidity and mortality. Although no results are available from randomized clinical trials assessing the FDC tablet of sitagliptin/simvastatin, the results from controlled clinical studies of the individual treatments provide information on their respective efficacy that may be extrapolated to infer efficacy and safety of the FDC.

\section{Sitagliptin}

Four randomized double-blind placebo-controlled trials of 12 to 24 weeks in duration were conducted in type 2 diabetic subjects who were drug-naïve or whose prior treatment with 
OHAs had been discontinued. ${ }^{47-50}$ These studies demonstrated that treatment with sitagliptin monotherapy resulted in significantly greater reductions from baseline in $\mathrm{HbA}_{1 \mathrm{C}}$ (placebo-subtracted $\mathrm{HbA}_{1 \mathrm{C}}$ reductions ranged from $-0.48 \%$ to $-0.94 \%$ ), as well as a significantly greater proportion of subjects achieving $\mathrm{HbA}_{1 \mathrm{C}}<7 \%$ compared with placebo. ${ }^{47-50} \mathrm{In}$ these studies, the usual clinical dose of sitagliptin was $100 \mathrm{mg}$ daily. Two of the studies also assessed a $200 \mathrm{mg}$ dose, ${ }^{47,50}$ and one of the studies used $50 \mathrm{mg}$ or $100 \mathrm{mg}$ as needed in elderly patients who had moderate renal insufficiency. ${ }^{48}$ In addition, these same trials showed that sitagliptin treatment, compared with placebo, resulted in significantly greater reductions in fasting plasma glucose (FPG) and 2-hour post-meal glucose, and significantly improved homeostatic model assessments (HOMA- $\beta)^{47-50}$ and pro-insulin/insulin ratio. ${ }^{47,48,50}$ Results from a study that was extended from 1 to 2 years indicated that sitagliptin as monotherapy or as initial combination therapy with metformin (500 mg or $1000 \mathrm{mg}$ twice daily) provided substantial and sustained glycemic control for up to 2 years. ${ }^{51,52}$ Generally, the beneficial effect of sitagliptin on $\mathrm{HbA}_{1 \mathrm{C}}$ versus placebo was consistent among subgroups defined by age, sex, race, baseline BMI, and prior use of OHAs. ${ }^{47-50,53,54}$ One study specifically assessed type 2 diabetic subjects older than 65 years, and showed significantly greater reductions in $\mathrm{HbA}_{1 \mathrm{C}}$, 2-hour post-meal glucose, and FPG, as well as improvements in HOMA- $\beta$ over 24 weeks with sitagliptin (100 mg once daily or $50 \mathrm{mg}$ once daily, dependent on renal function) compared with placebo, consistent with reports in younger subjects. ${ }^{48}$ Moreover, four additional studies confirmed these findings in Asian populations: three in Japanese subjects and one each in Chinese, Indian, and Korean subjects (placebo-subtracted $\mathrm{HbA}_{1 \mathrm{C}}$ reductions ranged from $-0.96 \%$ to $-1.4 \%$ ), as well as showing significant improvements in indices of glycemic control such as FPG, 2-hour post-meal glucose, and HOMA- $\beta$ in these populations. ${ }^{55-58}$

Sitagliptin has also been assessed in subjects inadequately controlled on single or dual OHA therapy or single OHA plus insulin at study entry. Eight clinical trials (sitagliptin $100 \mathrm{mg} /$ day once daily added to metformin $\geq$ $1500 \mathrm{mg} /$ day ${ }^{59-61}$ insulin $\geq 15 \mathrm{IU} /$ day alone or combined with metformin $\geq 1500 \mathrm{mg} /$ day $;{ }^{62}$ metformin $\geq 1500 \mathrm{mg} /$ day plus rosiglitazone $\geq 4 \mathrm{mg} / \mathrm{day} ;{ }^{63}$ glimepiride $\geq 4 \mathrm{mg}$ /day or glimepiride $\geq 4 \mathrm{mg} /$ day plus metformin $\geq 1500 \mathrm{mg} /$ day ${ }^{64}$ ongoing metformin $\geq 1500 \mathrm{mg} /$ day and pioglitazone $\geq$ $30 \mathrm{mg} /$ day; ${ }^{65}$ or pioglitazone $30-45 \mathrm{mg} /$ day $^{66}$ ) demonstrated significantly greater reductions in $\mathrm{HbA}_{1 \mathrm{C}}$ (placebosubtracted $\mathrm{HbA}_{1 \mathrm{C}}$ reductions ranged from $-0.5 \%$ to $-1.0 \%$; all $P<0.001$ ), as well as a significantly greater proportion of subjects achieving $\mathrm{HbA}_{1 \mathrm{C}}<7 \%$ and significantly greater improvements in FPG versus placebo (all $P<0.001$ ). In the seven studies that assessed 2-hour post-meal glucose, significantly greater reductions were observed with sitagliptin add-on treatment versus placebo (all $P<0.001) .{ }^{59-65}$ Several studies also demonstrated significant improvements in HOMA- $\beta,{ }^{59-61,63,65}$ pro-insulin, ${ }^{66}$ pro-insulin/insulin ratio, ${ }^{63,65}$ and fasting insulin secretion, ${ }^{60}$ which supports the premise that treatment with sitagliptin improves beta-cell function. When sitagliptin $100 \mathrm{mg}$ add-on was compared with glipizide $5-20 \mathrm{mg} /$ day added on to metformin $\geq 1500 \mathrm{mg} /$ day, noninferiority in $\mathrm{HbA}_{1 \mathrm{C}}$ lowering was demonstrated at the 1-year time point (as noted above ${ }^{59}$ ) and no meaningful differences were observed during the 1-year extension period, although no inferential testing was conducted for the results of the extension. ${ }^{67}$ Compared with glipizide over 2 years, greater durability and generally better maintenance of beta-cell function were observed with sitagliptin $100 \mathrm{mg} .{ }^{67}$ In another trial comparing sitagliptin or rosiglitazone with placebo when added on to metformin, similar changes from baseline in $\mathrm{HbA}_{1 \mathrm{C}}$ and HOMA- $\beta$, and similar proportions of subjects achieving $\mathrm{HbA}_{1 \mathrm{C}}<7 \%$, were observed in subjects taking either active treatment regimen. ${ }^{61}$ As in the studies of subjects who were drug-naïve or discontinued from prior treatment, the greater effect of sitagliptin on $\mathrm{HbA}_{1 \mathrm{C}}$ versus placebo was consistent among subgroups defined by age, sex, race, baseline BMI, and prior use of OHAs. ${ }^{60-64,66,68}$ In the majority of clinical trials, both add-on and drug-naïve/-washout, there was a significant interaction between baseline $\mathrm{HbA}_{1 \mathrm{C}}$ and treatment effect. ${ }^{60,61,63,64,66,68,69}$ Specifically, in subjects with higher baseline $\mathrm{HbA}_{1 \mathrm{C}}$, reductions in $\mathrm{HbA}_{1 \mathrm{C}}$ were greater than in subjects with lower baseline $\mathrm{HbA}_{1 \mathrm{C}}{ }^{*}{ }^{47-50,53,54,60,61,63,64,66,68,69}$ Overall, sitagliptin has been shown to improve glycemic control and beta-cell function in type 2 diabetic patients both as a monotherapy and as combination therapy in clinical trials. Most of these trials were relatively short-term, and more long-term studies are needed to confirm the extended effects on glycemic control and beta-cell function.

\section{Simvastatin}

The benefits of cholesterol-lowering with simvastatin in the general population have been well-established. The Scandinavian Simvastatin Survival Study (4S) assessed the efficacy of simvastatin $20-40 \mathrm{mg}$ /day versus placebo in 4444 subjects with coronary heart disease for a median duration of 5.4 years. ${ }^{17}$ Simvastatin treatment resulted in mean reductions in total cholesterol, LDL-C, and triglycerides of 
$25 \%, 35 \%$, and $10 \%$, respectively, increased HDL-C by $8 \%$, and demonstrated a $42 \%$ reduction in the risk of coronary death compared with placebo (relative risk $[\mathrm{RR}]=0.58,95 \%$ CI $0.46-0.73 ; P=0.0003)$. Moreover, simvastatin treatment resulted in a significant reduction in the risk of a major coronary event including coronary death, nonfatal definite or probable myocardial infarction (MI), silent $\mathrm{MI}$, or resuscitated cardiac arrest compared with placebo $(\mathrm{RR}=0.66,95 \%$ CI $0.59-0.75 ; P<0.00001)$. These results were consistent in women and in subjects $\geq 60$ years. ${ }^{17}$ The Heart Protection Study, a placebo-controlled double-blind study conducted with 20,532 patients at high risk of developing a major coronary event (ie, subjects with known coronary disease, other occlusive arterial disease, or diabetes), compared treatment with simvastatin $40 \mathrm{mg}$ /day versus placebo with respect to all-cause death and death from coronary heart disease over 5 years of treatment. ${ }^{70}$ The placebo-adjusted differences between groups in total cholesterol, LDL-C, and triglycerides were $-0.8 \mathrm{mmol} / \mathrm{L},-1.0 \mathrm{mmol} / \mathrm{L}$, and $-0.2 \mathrm{mmol} / \mathrm{L}$, respectively. Simvastatin $40 \mathrm{mg} /$ day significantly reduced all-cause mortality $(P<0.0003)$ and coronary death rate (18\%, $P=0.0005)$, as well as producing a $38 \%$ reduction in the incidence of first nonfatal MI $(P<0.0001)$, a $25 \%$ reduction in first stroke $(P<0.0001)$, and a $24 \%$ reduction in first revascularization procedure $(P<0.0001){ }^{70}$

In addition to clinical outcomes and lipid-lowering in the general population, the benefits of simvastatin have also been assessed specifically in diabetic subjects. In a post hoc analysis of the $4 \mathrm{~S}$ trial that included subjects with diabetes or impaired fasting glucose, reductions in cholesterol levels and the risk of cardiovascular events were consistent with those observed in the full cohort. ${ }^{71}$ Diabetic subjects treated with simvastatin experienced a significantly reduced incidence of major coronary events $(\mathrm{RR}=0.58 ; P=0.001)$ and revascularizations ( $\mathrm{RR}=0.52 ; P=0.005)$ compared with placebo, and subjects with impaired fasting glucose also had significantly reduced incidence of major coronary events $(\mathrm{RR}=0.62$; $P=0.003)$, revascularization $(\mathrm{RR}=0.57 ; P=0.009)$, and total and coronary mortality $(\mathrm{RR}=0.57 ; P=0.02$ and $\mathrm{RR}=0.45$; $P=0.007$, respectively) compared with placebo. ${ }^{71}$ Analysis of the HPS also assessed simvastatin efficacy in subjects with and without diabetes and showed an effect consistent with the full cohort; ${ }^{72}$ that is, simvastatin produced highly significant reductions $(22 \% ; P<0.0001)$ in the first event rate for major coronary events, strokes, and revascularizations in subjects with type 2 diabetes. Furthermore, in type 2 diabetic subjects without occlusive arterial disease or other coronary arterial disease, the reductions were even higher (33\%; $P<0.0003)$. Based on these results, the authors concluded that cholesterol-lowering statin therapy can have a beneficial effect on coronary outcomes in type 2 diabetic patients even if they do not have coronary artery or other occlusive arterial disease.

\section{Safety and tolerability Sitagliptin}

The safety and tolerability profile of sitagliptin was assessed in 10,246 subjects with type 2 diabetes mellitus by pooling results from 19 controlled clinical trials (conducted for up to 2 years), comparing sitagliptin $(n=5429)$ with either placebo or active comparator (non-exposed group, $n=4817$ ). ${ }^{73}$ Reports of overall adverse events, serious adverse events, and the number of deaths were similar in the sitagliptin-treated and non-exposed groups, except for a higher incidence of drug-related adverse events in the non-exposed group. This was primarily attributed to the higher rate of hypoglycemia in the non-exposed group (mainly due to use of a sulfonylurea as a comparator agent in two studies). In a separate pooled analysis that removed sulfonylureas and insulin as background or comparator, the incidence rates of hypoglycemia were similar between groups (3.1 versus 3.3 per 100 patientyears in sitagliptin and non-exposed groups, respectively). ${ }^{73}$ There was a greater number of reports of diarrhea in the non-exposed group, likely due to the use of metformin, and more reports of constipation in the sitagliptin group. ${ }^{73}$ In addition to hypoglycemia, abdominal pain, diarrhea, gastritis, weight gain, and paresthesia were reported more often in the non-exposed group compared with the sitagliptin group. Constipation was the only drug-related adverse event reported more often in the sitagliptin-treated group. ${ }^{73}$

\section{Simvastatin}

In general, statins have been shown to be safe and well-tolerated in clinical trials. However, important adverse events that are associated with statin use include muscle complaints, ranging from muscle weakness and cramps to myalgia (with and without elevated creatine kinase levels) and rhabdomyolysis, as well as increases in liver enzymes $>3$ times the upper limit of normal. ${ }^{74,75}$ The risk of muscle toxicity may be increased in certain patients, including older individuals ( $\geq 75$ years), those with comorbid conditions and/or taking concomitant medications, and those with impaired hepatic or renal function. ${ }^{74,76}$ In addition, higher statin doses (eg, simvastatin $80 \mathrm{mg}$ ) may increase the risk to a greater extent than moderate doses. In 2011, new dosing recommendations for simvastatin were introduced worldwide based on the dose-response relationship to the risk of myopathy, and the $80 \mathrm{mg}$ dose of simvastatin is limited to patients who have been taking it for 12 months or 
more without evidence of myopathy. ${ }^{77}$ Although the labeling for every statin reflects a warning for each agent's potential for myotoxicity, both observational and clinical trial data indicate that the risk of myotoxicity and rhabdomyolysis is low for all marketed statins. ${ }^{78}$ Increases in liver transaminases have also been reported with statin use compared with placebo, and these are commonly reversible with discontinuation of treatment or dose reduction. ${ }^{79}$

Recently, there has been concern regarding the effect of statins on glycemia and new-onset type 2 diabetes. Results of the JUPITER trial ${ }^{80}$ and a large meta-analysis of statin trials $^{81}$ suggested a slight increase in the risk of new onset of type 2 diabetes with the use of statins. Because of these concerns, many statins, including simvastatin, contain a statement regarding this issue in the "warnings and precautions" section of the prescribing information..$^{42}$ The Juvisync ${ }^{\mathrm{TM}}$ prescribing information also contains a statement regarding this issue in the "warnings and precautions" section. ${ }^{82}$ The effects of simvastatin treatment on glucose control in type 2 diabetic patients have been evaluated in clinical trials. In the HPS study, after a 4.6 year follow up $(\mathrm{n}=1087)$, there was no significant difference between treatment groups in the increase in $\mathrm{HbA}_{1 \mathrm{C}}$ concentration $(0.15 \%$ [standard deviation $(\mathrm{SD})=0.09]$ versus $0.12 \%$ [SD $=0.09]$, difference $0.03 \%$ $[\mathrm{SD}=0.13] ; P=0.8)$, suggesting that simvastatin did not affect diabetes control in this study. ${ }^{72}$ Moreover, in this study, simvastatin treatment did not result in any increases in reports of other diabetes-related outcomes, such as hospital admissions for unstable diabetes or laser treatments for retinopathy, in the 5963 participants known to have diabetes. ${ }^{72}$ In a smaller double-blind placebo-controlled trial that assessed the efficacy of simvastatin $20-40 \mathrm{mg} /$ day for 6 months in subjects with non-insulin-dependent diabetes mellitus, there were no significant changes in measures of glycemic control, including fasting plasma glucose, insulin, C-Peptide, or $\mathrm{HbA}_{1 \mathrm{C}}$, with simvastatin treatment. ${ }^{83}$

Finally, concerns were raised that statin use could increase the risk of cancers that take longer than 5 years to emerge clinically. ${ }^{84}$ Three separate trials with extended follow-up of 15 years (including 5 years of in-trial follow-up) ${ }^{85} 11.3$ years (including 3.3 years of in-trial follow-up) ${ }^{86}$ and 11 years (including 5.3 years of in-trial follow-up) ${ }^{86}$ showed consistently that incident cancer did not increase in the statin treated subjects compared with placebo groups.

\section{Coadministration and fixed-dose combination}

In a pooled subgroup analysis of 19 clinical studies of sitagliptin including 1582 patients whose background therapy included simvastatin, the incidence of adverse events was similar between patients treated with sitagliptin and simvastatin $(\mathrm{n}=827)$ and patients treated with placebo or active comparator and simvastatin $(\mathrm{n}=755){ }^{73,82}$ Among the patients whose background therapy included simvastatin, $3.3 \%$ of the sitagliptin-treated group and $4.2 \%$ of controls discontinued due to adverse events. ${ }^{82}$ The short-term bioequivalence studies (described above) assessing the pharmacological profile of the FDC sitagliptin/simvastatin also provide some insight into the safety and tolerability profiles. In both studies that assessed bioequivalence, there were no serious adverse experiences or serious laboratory adverse events reported, and no subjects discontinued due to an adverse event. It is important to note that the bioequivalence studies were open label single-dose studies conducted in healthy subjects rather than in patients with diabetes, and the results should therefore be interpreted with caution. The safety results of the bioequivalence studies indicate that the coadministration of sitagliptin and simvastatin was generally well tolerated and without indication of emergent clinical or laboratory safety signals when dosed acutely.

\section{Conclusion}

Cardiovascular risk is increased in patients with diabetes, including in those with normal LDL-C levels. ${ }^{6}{ }^{10}$ Addressing this risk will require statin treatment in most patients. ${ }^{6}$ However, underutilization and insufficient intensification of statins and OHA treatment may contribute to a failure to achieve recommended treatment targets. In addition to patient counseling on lifestyle changes and adherence to medication regimens, patients may benefit from use of FDC therapies, which have been shown to increase adherence through reducing pill burden, complexity of treatment regimen, and cost. ${ }^{37,38,87}$ Based on the available evidence regarding the pharmacokinetics, efficacy, and safety profile of each component drug, the sitagliptin/simvastatin FDC may provide a well-tolerated approach to achieving improved lipid lowering and glycemic control, with consequent reduction in cardiovascular risk, diabetic microvascular disease, and mortality in diabetic patients for whom treatment with both compounds is appropriate.

\section{Acknowledgment}

The authors would like to thank Dr Jennifer Rotonda, PhD, of Merck Sharp \& Dohme Corp. for assistance with preparation of the manuscript.

\section{Disclosure}

All authors are employees of Merck Sharp \& Dohme Corp. and may own stock or hold stock options in the company. The authors report no other conflicts of interest in this work. 


\section{References}

1. International Diabetes Federation. IDF Diabetes Atlas, 5th edn. 2012 Update. Brussels, Belgium: International Diabetes Federation, 2012.

2. National Diabetes Fact Sheet: National Estimates and General Information on Diabetes and Prediabetes in the United States, 2011. Atlanta, GA: US Department of Health and Human Services, Centers for Disease Control and Prevention; 2011.

3. Stamler J, Vaccaro O, Neaton JD, Wentworth D. Diabetes, other risk factors, and 12-yr cardiovascular mortality for men screened in the Multiple Risk Factor Intervention Trial. Diabetes Care. 1993;16:434-444.

4. Stevens RJ, Kothari V, Adler AI, Stratton IM. The UKPDS risk engine: a model for the risk of coronary heart disease in Type II diabetes (UKPDS 56). Clin Sci (Lond). 2001;101:671-679.

5. Turner RC, Millns H, Neil HA, et al. Risk factors for coronary artery disease in non-insulin dependent diabetes mellitus: United Kingdom Prospective Diabetes Study (UKPDS: 23). BMJ. 1998;316:823-828.

6. Brunzell JD, Davidson M, Furberg CD, et al. Lipoprotein management in patients with cardiometabolic risk: consensus conference report from the American Diabetes Association and the American College of Cardiology Foundation. J Am Coll Cardiol. 2008;51:1512-1524.

7. Anber V, Griffin BA, McConnell M, Packard CJ, Shepherd J. Influence of plasma lipid and LDL-subfraction profile on the interaction between low density lipoprotein with human arterial wall proteoglycans. Atherosclerosis. 1996;124:261-271.

8. Nigon F, Lesnik P, Rouis M, Chapman MJ. Discrete subspecies of human low density lipoproteins are heterogeneous in their interaction with the cellular LDL receptor. J Lipid Res. 1991;32:1741-1753.

9. Tribble DL, Holl LG, Wood PD, Krauss RM. Variations in oxidative susceptibility among six low density lipoprotein subfractions of differing density and particle size. Atherosclerosis. 1992;93:189-199.

10. Grundy SM. Atherogenic dyslipidemia associated with metabolic syndrome and insulin resistance. Clin Cornerstone. 2006;8 Suppl 1: S21-S27.

11. National Cholesterol Education Program (NCEP) Expert Panel on Detection, Evaluation, and Treatment of High Blood Cholesterol in Adults (Adult Treatment Panel III). Third Report of the National Cholesterol Education Program (NCEP) Expert Panel on Detection, Evaluation, and Treatment of High Blood Cholesterol in Adults (Adult Treatment Panel III) final report. Circulation. 2002;106: 3143-3421.

12. Catapano AL, Reiner Z, De Backer G, et al. ESC/EAS Guidelines for the management of dyslipidaemias The Task Force for the management of dyslipidaemias of the European Society of Cardiology (ESC) and the European Atherosclerosis Society (EAS). Atherosclerosis. 2011;217:3-46.

13. Genest J, McPherson R, Frohlich J, et al. 2009 Canadian Cardiovascular Society/Canadian guidelines for the diagnosis and treatment of dyslipidemia and prevention of cardiovascular disease in the adult - 2009 recommendations. Can J Cardiol. 2009;25:567-579.

14. Anderson TJ, Gregoire J, Hegele RA, et al. 2012 update of the canadian cardiovascular society guidelines for the diagnosis and treatment of dyslipidemia for the prevention of cardiovascular disease in the adult. Can J Cardiol. 2013;29:151-167.

15. Expert Panel on Detection, Evaluation, and Treatment of High Blood Cholesterol in Adults. Executive Summary of The Third Report of The National Cholesterol Education Program (NCEP) Expert Panel on Detection, Evaluation, And Treatment of High Blood Cholesterol In Adults (Adult Treatment Panel III). JAMA. 2001;285: 2486-2497.

16. American Diabetes Association. Standards of medical care in diabetes - 2009. Diabetes Care. 2009;32 Supp1 1:S13-S61.

17. [No authors listed]. Randomised trial of cholesterol lowering in 4444 patients with coronary heart disease: the Scandinavian Simvastatin Survival Study (4S). Lancet. 1994;344:1383-1389.

18. Cannon CP, Braunwald $\mathrm{E}, \mathrm{McCabe} \mathrm{CH}$, et al. Intensive versus moderate lipid lowering with statins after acute coronary syndromes. $N$ Engl J Med. 2004;350:1495-1504.
19. LaRosa JC, Grundy SM, Waters DD, et al. Intensive lipid lowering with atorvastatin in patients with stable coronary disease. $N$ Engl J Med. 2005;352:1425-1435.

20. Baigent C, Keech A, Kearney PM, et al. Efficacy and safety of cholesterol-lowering treatment: prospective meta-analysis of data from 90,056 participants in 14 randomised trials of statins. Lancet. 2005;366: 1267-1278.

21. Kearney PM, Blackwell L, Collins R, et al. Efficacy of cholesterollowering therapy in 18,686 people with diabetes in 14 randomised trials of statins: a meta-analysis. Lancet. 2008;371:117-125.

22. Rydén L, Standl E, Bartnik M, et al; Task Force on Diabetes and Cardiovascular Diseases of the European Society of Cardiology (ESC); European Association for the Study of Diabetes (EASD). Guidelines on diabetes, pre-diabetes, and cardiovascular diseases: executive summary. The Task Force on Diabetes and Cardiovascular Diseases of the European Society of Cardiology (ESC) and of the European Association for the Study of Diabetes (EASD). Eur Heart J. 2007;28:88-136.

23. [No authors listed]. The effect of intensive treatment of diabetes on the development and progression of long-term complications in insulindependent diabetes mellitus. The Diabetes Control and Complications Trial Research Group. N Engl J Med. 1993;329:977-986.

24. Stratton IM, Adler AI, Neil HA, et al. Association of glycaemia with macrovascular and microvascular complications of type 2 diabetes (UKPDS 35): prospective observational study. BMJ. 2000;321:405-412.

25. Ho PM, Rumsfeld JS, Masoudi FA, et al. Effect of medication nonadherence on hospitalization and mortality among patients with diabetes mellitus. Arch Intern Med. 2006;166:1836-1841.

26. Cramer JA. A systematic review of adherence with medications for diabetes. Diabetes Care. 2004;27:1218-1224.

27. Yeaw J, Benner JS, Walt JG, Sian S, Smith DB. Comparing adherence and persistence across 6 chronic medication classes. J Manag Care Pharm. 2009; 15:728-740.

28. Priest JL, Cantrell CR, Fincham J, Cook CL, Burch SP. Quality of care associated with common chronic diseases in a 9-state Medicaid population utilizing claims data: an evaluation of medication and health care use and costs. Popul Health Manag. 2011;14:43-54.

29. Briesacher BA, Andrade SE, Fouayzi H, Chan KA. Comparison of drug adherence rates among patients with seven different medical conditions. Pharmacotherapy. 2008;28:437-443.

30. Zhang Q, Zhao C, Davies MJ, Radican L, Seck T. Compliance and persistence with concomitant statin and oral antihyperglycemic therapy. Am J Manag Care. 2011;17:746-752.

31. Phillips LS, Branch WT, Cook CB, et al. Clinical inertia. Ann Intern Med. 2001;135:825-834.

32. American Diabetes Association. Standards of medical care in diabetes - 2011. Diabetes Care. 2011;34 Suppl 1:S11-S61.

33. Merz CN, Buse JB, Tuncer D, Twillman GB. Physician attitudes and practices and patient awareness of the cardiovascular complications of diabetes. J Am Coll Cardiol. 2002;40:1877-1881.

34. Chahil TJ, Ginsberg HN. Diabetic dyslipidemia. Endocrinol Metab Clin North Am. 2006;35:491-510, vii-viii.

35. Kiortsis DN, Giral P, Bruckert E, Turpin G. Factors associated with low compliance with lipid-lowering drugs in hyperlipidemic patients. J Clin Pharm Ther. 2000;25:445-451.

36. LaRosa JH, LaRosa JC. Enhancing drug compliance in lipid-lowering treatment. Arch Fam Med. 2000;9:1169-1175.

37. Cheong C, Barner JC, Lawson KA, Johnsrud MT. Patient adherence and reimbursement amount for antidiabetic fixed-dose combination products compared with dual therapy among Texas Medicaid recipients. Clin Ther. 2008;30:1893-1907.

38. Pan F, Chernew ME, Fendrick AM. Impact of fixed-dose combination drugs on adherence to prescription medications. J Gen Intern Med. 2008;23:611-614.

39. Thayer S, Arondekar B, Harley C, Darkow TE. Adherence to a fixeddose combination of rosiglitazone/glimepiride in subjects switching from monotherapy or dual therapy with a thiazolidinedione and/or a sulfonylurea. Ann Pharmacother. 2010;44:791-799. 
40. Drucker DJ, Nauck MA. The incretin system: glucagon-like peptide-1 receptor agonists and dipeptidyl peptidase-4 inhibitors in type 2 diabetes. Lancet. 2006;368:1696-1705.

41. Herman GA, Stein PP, Thornberry NA, Wagner JA. Dipeptidyl peptidase-4 inhibitors for the treatment of type 2 diabetes: focus on sitagliptin. Clin Pharmacol Ther. 2007;81:761-767.

42. Zocor (simvastatin) tablets [package insert]. Whitehouse Station, NJ: Merck and Co, Inc; 2011.

43. Pham DQ, Nogid A, Plakogiannis R. Sitagliptin: a novel agent for the management of type 2 diabetes mellitus. Am J Health Syst Pharm. 2008;65:521-531.

44. Mauro VF. Clinical pharmacokinetics and practical applications of simvastatin. Clin Pharmacokinet. 1993;24:195-202.

45. Cerra M, Luo WL, Li SX, et al. The effects of simvastatin on the pharmacokinectics of sitagliptin. J Popul Ther Clin Pharmacol. 2012;19: e356-e360.

46. Bergman AJ, Cote J, Maes A, et al. Effect of sitagliptin on the pharmacokinetics of simvastatin. J Clin Pharmacol. 2009;49:483-488.

47. Aschner P, Kipnes MS, Lunceford JK, Sanchez M, Mickel C, WilliamsHerman DE. Effect of the dipeptidyl peptidase-4 inhibitor sitagliptin as monotherapy on glycemic control in patients with type 2 diabetes. Diabetes Care. 2006;29:2632-2637.

48. Barzilai N, Guo H, Mahoney EM, et al. Efficacy and tolerability of sitagliptin monotherapy in elderly patients with type 2 diabetes: a randomized, double-blind, placebo-controlled trial. Curr Med Res Opin. 2011;27:1049-1058.

49. Goldstein BJ, Feinglos MN, Lunceford JK, Johnson J, WilliamsHerman DE. Effect of initial combination therapy with sitagliptin, a dipeptidyl peptidase-4 inhibitor, and metformin on glycemic contro in patients with type 2 diabetes. Diabetes Care. 2007;30:1979-1987.

50. Raz I, Hanefeld M, Xu L, Caria C, Williams-Herman D, Khatami H. Efficacy and safety of the dipeptidyl peptidase-4 inhibitor sitagliptin as monotherapy in patients with type 2 diabetes mellitus. Diabetologia. 2006;49:2564-2571

51. Williams-Herman D, Johnson J, Teng R, et al. Efficacy and safety of initial combination therapy with sitagliptin and metformin in patients with type 2 diabetes: a 54-week study. Curr Med Res Opin. 2009;25: 569-583.

52. Williams-Herman D, Johnson J, Teng R, et al. Efficacy and safety of sitagliptin and metformin as initial combination therapy and as monotherapy over 2 years in patients with type 2 diabetes. Diabetes Obes Metab. 2010;12:442-451.

53. Aschner P, Katzeff HL, Guo H, et al. Efficacy and safety of monotherapy of sitagliptin compared with metformin in patients with type 2 diabetes. Diabetes Obes Metab. 2010;12:252-261.

54. Hanefeld M, Herman GA, Wu M, Mickel C, Sanchez M, Stein PP. Once-daily sitagliptin, a dipeptidyl peptidase- 4 inhibitor, for the treatment of patients with type 2 diabetes. Curr Med Res Opin. 2007;23: 1329-1339.

55. Iwamoto Y, Taniguchi T, Nonaka K, et al. Dose-ranging efficacy of sitagliptin, a dipeptidyl peptidase-4 inhibitor, in Japanese patients with type 2 diabetes mellitus. Endocr J. 2010;57:383-394.

56. Mohan V, Yang W, Son HY, et al. Efficacy and safety of sitagliptin in the treatment of patients with type 2 diabetes in China, India, and Korea. Diabetes Res Clin Pract. 2009;83:106-116.

57. Nonaka K, Kakikawa T, Sato A, et al. Efficacy and safety of sitagliptin monotherapy in Japanese patients with type 2 diabetes. Diabetes Res Clin Pract. 2008;79:291-298.

58. Nonaka K, Tsubouchi H, Okuyama K, Fukao Y, Johnson-Levonas AO, Amatruda JM. Effects of once-daily sitagliptin on 24-h glucose control following 4 weeks of treatment in Japanese patients with type 2 diabetes mellitus. Horm Metab Res. 2009;41:232-237.

59. Charbonnel B, Karasik A, Liu J, Wu M, Meininger G. Efficacy and safety of the dipeptidyl peptidase-4 inhibitor sitagliptin added to ongoing metformin therapy in patients with type 2 diabetes inadequately controlled with metformin alone. Diabetes Care. 2006;29: 2638-2643.
60. Raz I, Chen Y, Wu M, et al. Efficacy and safety of sitagliptin added to ongoing metformin therapy in patients with type 2 diabetes. Curr Med Res Opin. 2008;24:537-550.

61. Scott R, Loeys T, Davies MJ, Engel SS. Efficacy and safety of sitagliptin when added to ongoing metformin therapy in patients with type 2 diabetes. Diabetes Obes Metab. 2008;10:959-969.

62. Vilsboll T, Rosenstock J, Yki-Jarvinen H, et al. Efficacy and safety of sitagliptin when added to insulin therapy in patients with type 2 diabetes. Diabetes Obes Metab. 2010;12:167-177.

63. Dobs AS, Goldstein BJ, Aschner P, et al. Efficacy and safety of sitagliptin added to ongoing metformin and rosiglitazone combination therapy in a randomized, placebo-controlled, 54-week trial in patients with type 2 diabetes. $J$ Diabetes. 2013;5:68-79.

64. Hermansen K, Kipnes M, Luo E, Fanurik D, Khatami H, Stein P. Efficacy and safety of the dipeptidyl peptidase-4 inhibitor, sitagliptin, in patients with type 2 diabetes mellitus inadequately controlled on glimepiride alone or on glimepiride and metformin. Diabetes Obes Metab. 2007;9:733-745.

65. Fonseca V, Staels B, Morgan II JD, et al. Efficacy and safety of sitagliptin added to ongoing metformin and pioglitazone combination therapy in a randomized, placebo-controlled, 26-week trial in patients with type 2 diabetes. J Diabetes Complications. 2013;27:177-183.

66. Rosenstock J, Brazg R, Andryuk PJ, Lu K, Stein P. Efficacy and safety of the dipeptidyl peptidase-4 inhibitor sitagliptin added to ongoing pioglitazone therapy in patients with type 2 diabetes: a 24-week, multicenter, randomized, double-blind, placebo-controlled, parallelgroup study. Clin Ther. 2006;28:1556-1568.

67. Seck T, Nauck M, Sheng D, et al. Safety and efficacy of treatment with sitagliptin or glipizide in patients with type 2 diabetes inadequately controlled on metformin: a 2-year study. Int J Clin Pract. 2010;64: $562-576$

68. Yoon KH, Shockey GR, Teng R, et al. Effect of initial combination therapy with sitagliptin, a dipeptidyl peptidase-4 inhibitor, and pioglitazone on glycemic control and measures of beta-cell function in patients with type 2 diabetes. Int J Clin Pract. 2011;65:154-164.

69. Reasner C, Olansky L, Seck TL, et al. The effect of initial therapy with the fixed-dose combination of sitagliptin and metformin compared with metformin monotherapy in patients with type 2 diabetes mellitus. Diabetes Obes Metab. 2011;13:644-652.

70. Heart Protection Study Collaborative Group. MRC/BHF Heart Protection Study of cholesterol lowering with simvastatin in 20,536 high-risk individuals: a randomised placebo-controlled trial. Lancet. 2002;360:7-22.

71. Haffner SM, Alexander CM, Cook TJ, et al. Reduced coronary events in simvastatin-treated patients with coronary heart disease and diabetes or impaired fasting glucose levels: subgroup analyses in the Scandinavian Simvastatin Survival Study. Arch Intern Med. 1999;159:2661-2667.

72. Collins R, Armitage J, Parish S, Sleigh P, Peto R; Heart Protection Study Collaborative Group. MRC/BHF Heart Protection Study of cholesterol-lowering with simvastatin in 5963 people with diabetes: a randomised placebo-controlled trial. Lancet. 2003;361:2005-2016.

73. Williams-Herman D, Engel SS, Round E, et al. Safety and tolerability of sitagliptin in clinical studies: a pooled analysis of data from 10,246 patients with type 2 diabetes. BMC Endocr Disord. 2010;10:7.

74. Escobar C, Echarri R, Barrios V. Relative safety profiles of high dose statin regimens. Vasc Health Risk Manag. 2008;4:525-533.

75. Talbert RL. Safety issues with statin therapy. JAm Pharm Assoc (2003). 2006; 46:479-488

76. Armitage J. The safety of statins in clinical practice. Lancet. 2007;370: $1781-1790$

77. [No authors listed]. New simvastatin dosing recommendations. Med Lett Drugs Ther. 2011;53:61-62.

78. Backes JM, Howard PA, Ruisinger JF, Moriarty PM. Does simvastatin cause more myotoxicity compared with other statins? Ann Pharmacother. 2009;43:2012-2020.

79. Bays H. Statin safety: an overview and assessment of the data -2005 . Am J Cardiol. 2006;97:6C-26C. 
80. Ridker PM, Pradhan A, MacFadyen JG, Libby P, Glynn RJ. Cardiovascular benefits and diabetes risks of statin therapy in primary prevention: an analysis from the JUPITER trial. Lancet. 2012;380: 565-571.

81. Sattar N, Preiss D, Murray HM, et al. Statins and risk of incident diabetes: a collaborative meta-analysis of randomised statin trials. Lancet. 2010;375:735-742.

82. Juvisync (sitagliptin and simvastatin) tablets [package insert]. Whitehouse Station, NJ: Merck and Co, Inc; 2012.

83. Farrer M, Winocour PH, Evans K, et al. Simvastatin in non-insulindependent diabetes mellitus: effect on serum lipids, lipoproteins and haemostatic measures. Diabetes Res Clin Pract. 1994;23:111-119.
84. Newman TB, Hulley SB. Carcinogenicity of lipid-lowering drugs. JAMA. 1996;275:55-60.

85. Ford I, Murray H, Packard CJ, Shepherd J, Macfarlane PW, Cobbe SM. Long-term follow-up of the West of Scotland Coronary Prevention Study. N Engl J Med. 2007;357:1477-1486.

86. Sever PS, Chang CL, Gupta AK, Whitehouse A, Poulter NR. The AngloScandinavian Cardiac Outcomes Trial: 11-year mortality follow-up of the lipid-lowering arm in the UK. Eur Heart J. 2011;32:2525-2532.

87. Blonde L, Wogen J, Kreilick C, Seymour AA. Greater reductions in A1C in type 2 diabetic patients new to therapy with glyburide/metformin tablets as compared to glyburide co-administered with metformin. Diabetes Obes Metab. 2003;5:424-431.

\section{Publish your work in this journal}

Vascular Health and Risk Management is an international, peerreviewed journal of therapeutics and risk management, focusing on concise rapid reporting of clinical studies on the processes involved in the maintenance of vascular health; the monitoring, prevention and treatment of vascular disease and its sequelae; and the involvement of metabolic disorders, particularly diabetes. This journal is indexed on PubMed Central and MedLine. The manuscript management system is completely online and includes a very quick and fair peer-review system, which is all easy to use. Visit http://www.dovepress.com/ testimonials.php to read real quotes from published authors. 